\title{
How Should We Do Nanoethics? A Network Approach for Discerning Ethical Issues in Nanotechnology
}

\author{
Ibo van de Poel
}

Received: 8 January 2008 / Accepted: 8 January 2008 /Published online: 28 February 2008

(C) The Author(s) 2008

\begin{abstract}
There is no agreement on how nanoethics should proceed. In this article I focus on approaches for discerning ethical issues in nanotechnology, which is as of yet one of the most difficult and urging tasks for nanoethics. I discuss and criticize two existing approaches for discerning ethical issues in nanotechnology and propose a network approach as alternative. I discuss debates in nanoethics about the desirable role of ethics in nanotechnological development and about the newness of ethical issues in nanotechnology. On basis of a critical analysis of both debates, I formulate a number of desiderata for a method for discerning ethical issues in nanotechnology and argue that the network approach that my colleagues and I have developed for ethical issues in research and development networks is also appropriate in nanotechnology.
\end{abstract}

Keywords Ethical issues · Ethics .

Moral methodology · Network analysis .

Nanotechnology $\cdot$ Nanoethics ·

Research and development

I. van de Poel $(\bowtie)$

School of Technology, Policy and Management,

Delft University of Technology,

P.O. Box 5015, 2600 GA Delft, The Netherlands

e-mail: i.r.vandepoel@tudelft.nl

\section{Introduction}

Nanotechnology has caught a lot of ethical concern and attention in the last few years. Several studies have taken stock of potential ethical issues that are raised by nanotechnology [4, 13, 22, 23, 26-28, 31, 33]. Such ethical issues include the environmental and health opportunities and risks of nanotechnology, in particular the potential risks of nanoparticles, privacy and control threats raised by the use of nanodevices, the possibilities for human disease treatment and enhancement and the ethical consequences thereof, and issues of equity, global justice and distribution of benefits and risks, including ethical issues with respect to patents and property rights.

The convergence in ethical aspects that are mentioned in various studies might lead to the impression that the ethical issues raised by nanotechnology are clear; what still need to be done is to analyze such issues and to make decisions about them, but no further efforts for discerning ethical issues are required. I think this impression is wrong for two reasons. First, nanoscience and nanotechnology are still in the very early phases of development; even if we might expect certain ethical issues to arise, it is difficult to predict all possible ethical issues beforehand. Focusing on a list of potential ethical issues based on today's knowledge might very well result in overlooking ethical issues in the future. Second, the available overviews of ethical issues in most cases are merely a taxonomy of types of 
ethical issues, like privacy or enhancement, rather than a description of specific ethical issues raised by specific scientific and technological developments. The tacit premise is that once such specific issues arise we will simply see them, without the need for a specific approach or method. I think this view is mistaken and based on rather context-free idea of what an ethical issue is, as if an ethical issue is fully described by, for example, the denominator 'privacy.' Obviously we have reason to expect that nanotechnology will raise privacy issues but that knowledge alone is not enough to discern the concrete ethical issues as they arise during the further development of nanotechnologies.

For these reasons, there is a need for methods for discerning ethical issues in nanotechnology. One might wonder what the proper subject of such method is. The answer seems to be nanotechnology. Yet, this answer might be too broad as well as too limited. It might be too broad because nanotechnology is not really one field of technology that raises one type of ethical issues. Rather, there is a whole range of nanotechnologies raising a whole range of ethical issues. Still, it might be argued that one thing that all nanotechnologies have in common is that they are new and innovative and still in development. This characteristic of nanotechnology makes it difficult to discern the relevant ethical issues and seems to ask for a new method or approach. So conceived, however, the label 'nanotechnology' might be too limited. It is difficult to discern ethical issues in the early phases of technological development also in other technological domains, and in these cases a similar method as for nanotechnology might be useful. ${ }^{1}$

Nanotechnology and other new technologies thus pose challenges that require new approaches for discerning ethical issues. In particular, I am thinking of the challenge of developing a method or approach that is (1) able to discern ethical issues while the technology is still in its very early phases of development and (2) to do so in such in way that these reflections can inform the process of technological development itself and (3) is able to identify specific contextualized ethical issues raised by specific technological and scientific developments rather than to

\footnotetext{
${ }^{1}$ Cf. the argument by Swierstra and Rip [30] that there might be a need for a NEST-ethics (NEST refers to new and emerging science and technology) even if there might not be a need for nanoethics.
}

describe the issues simply as privacy issues, safety issues, enhancement issues and the like.

In this article, I will propose a method that is, I claim, able to deal with these three challenges. This method is based on a network approach for discerning ethical issues in research and development (R\&D) that I developed together with Sjoerd Zwart, Michiel Brumsen and Harald van Mil [34, 37]. In this article, I will not explain the approach in all details because this has been done in other publications. Rather, my emphasis will be on arguing the adequacy of this method against the background of the challenges, existing approaches and debates in the ethics of nanotechnology.

I start this article with a brief overview of two existing approaches from the literature on ethics in nanotechnology for discerning ethical issues. I then turn to two relevant debates in the ethics of nanotechnology. These are the debate on the proper role of ethics in nanotechnological $R \& D$, and the debate on whether nanotechnology gives rise to any new ethical issues. On the basis of these discussions, I formulate a number of desiderata for an alternative approach. I then set out the network approach for discerning ethical issues in research and design, as it has been proposed by Zwart, Van de Poel, Van Mil and Brumsen [37] and I show why this approach meets the mentioned desiderata. I end with some critical remarks about the limitations of this approach and considerations that should be taken into account when employing it.

\section{Current Approaches}

Many of the early ethical concerns about nanotechnology had strong futuristic and science-fictional overtones [4, 9, 24, 27]. Futuristic science fiction stories about nanotechnology, both utopian and dystopian, were told and these formed the basis for ethical hopes, fears and concerns about nanotechnology. The grey goo scenario [7], in which out-ofcontrol and self-replicating nanodevices consume all the matter in the world is a typical example, but also many discussions about the possibility of human enhancement fit this pattern. Nordmann [24] has argued that such an approach is operating through an 'if ... then ...' line of reasoning. If some futuristic possibility or scenario will materialize then we are 
confronted with a certain moral problem or with a certain moral imperative. Typically the conditional if is incredible but is skipped over to focus on the moral issue or imperative. Nordmann calls such an approach 'speculative nanoethics.'

Still, one might argue that this type of approach is based on what Hans Jonas has called a 'heuristics of fear' [16]. According to Jonas, in the age of technology, the span of consequences of human action is much wider - geographically, in time, and in magnitude (the possible destruction of mankind) - than traditional ethics presupposes. We are therefore in need of a new ethics: an ethics of the future. A first duty of such an ethics is to visualize the long-term effects of technological developments:

Now, where this world is not vouchsafed us on its own - that is, by evil already present-it becomes our duty to seek it out by an effort of reason and imagination, so that it can instill in us the fear whose guidance we need. That is the case with the "ethics of the future" which we are looking for, where that which is to be feared has never yet happened and has perhaps no analogies in past or present experience. Then the creatively imagined malum has to take over the role of the experienced malum, and this imagination does not arise on its own but must be intentionally induced. Therefore the anticipatory conjuring up of this imagination becomes itself the first, as it were introductory, duty of the ethics we are speaking about ([16]: 27).

Many of the ethical worries, and of the promises, with respect to nanotechnology are indeed based on the use of imagination in a way very similar to what Jonas argues for in this quotation. It could be argued that such a use of imagination and the employment of a heuristics of fear can be useful to know what is at stake and might help to pay attention to such concerns in the early phases of technological development, i.e. in a phase that technology is still malleable.

Nevertheless, such an approach has a number of very serious drawbacks. ${ }^{2}$ It is not unrealistic to expect that many of the ethical issues that pop up as a consequence of the employment of a heuristics of fear

\footnotetext{
${ }^{2}$ See also Nordmann [24] for a sustained criticism of speculative nanoethics.
}

on the basis of futuristic or science fiction stories do never realize. This means that ethical concerns are raised 'unnecessarily'. Now, following Jonas, one might argue that this is a price that is worth paying if it helps to prevent a real future malum to happen. However, the price seems to be quite high and it is even not clear that this approach really helps against preventing future malum. First, imagining, analyzing and debating possible ethical concerns on the basis of a heuristics of fear costs resources and time that may well have been spend better. Second, it might lead to fears and stop technological developments that are actually quite promising for mankind. Third, once it becomes clear that the initial concerns were misperceived, it might lead to the conviction that no ethical concerns are raised by nanotechnology at all, resulting in a neglect of any ethical concerns about nanotechnology. Fourth, the heuristics of fear may well focus on the wrong ethical issues and therefore not be able to prevent future malum. It is not unlikely that the attention for imaginative but far-reaching ethical issues comes at the cost of attention for less imaginative, yet more realistic and often quite pervasive ethical issues.

Most of the early ethical concerns about nanotechnology were not raised by professional ethicists. Typically, more recent publications about ethical issues in nanotechnology by ethicists and social scientists employ a much more cautious approach to discerning ethical issues. A typical example is the stepwise methodological approach for discerning ethical issues that has recently been proposed by Brune et al. ([4]: 405). Their approach consists of three steps:

1. Literature and web search on ethics and nanotechnology

2. Evaluation of this material to see whether this raises any new ethical issues, i.e. ethical issues that cannot be dealt with the bounds of current normative frameworks $[11,12]$

3. Identifying possible gaps in the literature on ethics and nanotechnology on the basis of a schematic overview of nanotechnological research

Although this is an interesting and worthwhile approach, at least two critical questions can be raised.

The first question is whether this approach does enough to identify or discern the relevant ethical issues. Of course, discerning ethical issues is a noto- 
riously difficult task, but I think that more can be done than literature research and the identification of gaps on basis of a schematic overview of nanotechnological research. The alternative approach that is proposed in this article is based on closer interaction between nanotechnologists and ethicists in discerning ethical issues in the early phases of technological development.

The second question is whether the stepwise approach does not place too much emphasis on the newness of ethical issues. The implication of the stepwise approach seems to be that ethical issues only deserve attention if they are new. This touches on a broader debate in the ethics of nanotechnology on whether nanotechnology raises any new ethical issues. I will discuss this debate in some detail below and will argue that much of it is based on a wrong, or at least irrelevant, notion of 'newness.' Before I do so, I will first consider the debate on the desirable role of ethics in nanotechnological R\&D.

\section{The Desirable Role of Ethics in Nanotechnological R\&D}

In debates on the role of ethics in nanotechnology, ethics has both been presented as a means to set limits on the development of nanotechnology and nanotechnological R\&D, as well as a means to ease development of nanotechnology and to counter potential public fear and lack of acceptance. I think that both positions are seriously misconceived. Before explaining why I think so and proposing an alternative, I will first elaborate both positions by presenting the ideas of typical proponents of both positions.

Pleas for a Moratorium

The first vision is perhaps most prominent in the writings of computer scientist Bill Joy. In 2000, Joy wrote an article in Wired with the title 'Why the future does not need us' [17], which led to a lot of debate. In this article Joy wrote:

I think it is no exaggeration to say we are on the cusp of the further perfection of extreme evil, an evil whose possibility spreads well beyond that which weapons of mass destruction bequeathed to the nation-states, on to a surprising and terrible empowerment of extreme individuals.

Unfortunately, as with nuclear technology, it is far easier to create destructive uses for nanotechnology than constructive ones. Nanotechnology has clear military and terrorist uses, and you need not be suicidal to release a massively destructive nanotechnological device-such devices can be built to be selectively destructive, affecting, for example, only a certain geographical area or a group of people who are genetically distinct.

An immediate consequence of the Faustian bargain in obtaining the great power of nanotechnology is that we run a grave risk - the risk that we might destroy the biosphere on which all life depends. [...]

The only realistic alternative I see is relinquishment: to limit development of the technologies that are too dangerous, by limiting our pursuit of certain kinds of knowledge [17].

Joy thus argues for limits on the development of nanotechnology, and other technologies, because these technologies are very hazardous, especially when used with bad intentions. He even argues for limits on the production of knowledge, i.e. for a moratorium. In verifying compliance with the limits that are to be set, he sees a role for ethics:

Verifying compliance will ... require that scientists and engineers adopt a strong code of ethical conduct, resembling the Hippocratic oath, and that they have the courage to whistleblow as necessary, even at high personal cost [17].

Also others have called for a moratorium on certain nanotechnological developments on moral grounds. The Action Group on Erosion, Technology and Concentration (ETC group), for example, has pleaded for a moratorium on nanoparticles given the possible large dangers and negative health effects of these:

At this stage, we know practically nothing about the potential cumulative impact of human-made nano-scale particles on human health and the environment. Given the concerns raised over nanoparticle contamination in living organisms, governments should declare an immediate mora- 
torium on commercial production of new nanomaterials and launch a transparent global process for evaluating the socio-economic, health and environmental implications of the technology ([8]: 25).

It is interesting to note that the argument given by Joy and by the ETC group for a moratorium closely resembles Jonas' arguments for a heuristics of fear. ${ }^{3}$

\section{Promoting Nanotechnology}

While, according to Joy, the role of ethics in nanotechnological developments is to set limits and to contribute to verifying compliance with such limits, others see a quite different role for ethics. This opposite viewpoint is, for example, clearly visible in the National Nanotechnological Initiative (NNI) of the US. The foundational report for the NNI stated that:

The effect of nanotechnology on the health, wealth, and lives of people could be at least as significant as the combined influences of microelectronics, medical imaging, computer-aided engineering, and man-made polymers developed in this century (cited in [27]: 64).

Where Joy sees mainly dangers, the NNI stresses the benefits of nanotechnology. Nevertheless, the NNI sees an important role for ethics and ethical research. In the original press release of the White House for the NNI it was stated that:

Ethical, Legal, Societal Implications and Workforce Education and Training efforts will be undertaken to promote a new generation of skilled workers in the multidisciplinary perspectives necessary for rapid progress in nanotechnology ([36], my emphasis).

Typically, ethics is to contribute to rapid progress in nanotechnology, which is again completely opposite to Joy's point of view. Ethics is to do so by improving the communication from engineering and science to

\footnotetext{
${ }^{3}$ This is true in particular for Joy's argument. The call of the ETC group is more modest. It calls for more knowledge production about possible hazards before products are brought onto the market, whereas Joy calls for a moratorium on nanoscience. My criticism below is not directed against the content of the argument of the ETC group, but rather to the way the contribution of ethics to nanotechnology is implicitly framed.
}

society. As Schummer concludes on the basis of a reading of the various relevant US policy texts on nanotechnology and the NNI:

It seems that, for US policy makers, "societal concerns" ... means critical concerns by members or groups of the society, which can be ethical, legal, environmental, or other "appropriate" concerns, and which should be addressed and prevented by participatory models and education to make the American society "prepared" for nanotechnology. The broader concept, "societal implications", ... includes, ... the impact of ideas about future nanotechnology on such concerns, but excludes the impact of ideas in society on the development of nanotechnology ([27]: 66, my emphasis)

\section{Comparing the Positions}

Table 1 summarizes the positions taken in the debate. At first sight, Joy and the NNI flatly contradict each other on a number of relevant issues. However, a closer look shows that there are a number of common presuppositions in the reasoning of both Joy and the NNI. One is that we, by and large, know the expected effects of nanotechnology on society and that, on that basis, the ethical assessment of nanotechnology is clear. While Joy and the NNI make opposite ethical assessments of nanotechnology, they both presuppose that we already know enough to make such assessments. ${ }^{4}$ Second, both see ethics mainly as a means for communication. According to Joy, nanoscience listens too little to social concerns, which calls for an improvement of the communication from society to science. The NNI wants to improve the communication from science to society in order to take away allegedly unnecessary fears, and neglects the communication in the other direction. While Joy and the NNI disagree about the direction of the needed communication, both conceive of ethics primarily as a means for communication. Third, while both Joy and NNI see a role for ethics in influencing, either by inhibiting (Joy) or increasing (NNI), the pace of technological

\footnotetext{
${ }^{4}$ It is worth noting that the call for a moratorium by the ETC group is in this respect somewhat different because it calls for more knowledge production before we commercialize nanoproducts.
} 
Table 1 Overview of positions in the debate about the role of ethics in nanotechnological development

\begin{tabular}{|c|c|c|}
\hline & Joy & NNI \\
\hline $\begin{array}{l}\text { Expected effects on } \\
\text { society }\end{array}$ & Nanotechnology poses great risks for humanity & $\begin{array}{l}\text { Nanotechnology brings great benefits to } \\
\text { mankind }\end{array}$ \\
\hline $\begin{array}{l}\text { Drivers of } \\
\text { nanotechnological } \\
\text { development }\end{array}$ & $\begin{array}{l}\text { Development of nanotechnology is mainly } \\
\text { driven by economical and military considerations; } \\
\text { moral and social aspects are neglected, unless } \\
\text { enforced by society }\end{array}$ & $\begin{array}{l}\text { Development of nanotechnology may } \\
\text { well be inhibited because people distrust } \\
\text { nanotechnology due to lack of communication } \\
\text { and lack of knowledge }\end{array}$ \\
\hline Role of fear & $\begin{array}{l}\text { Useful, if not necessary, to discover what is } \\
\text { at stake and to trigger the right emotions for } \\
\text { addressing the ethical issues at stake }\end{array}$ & $\begin{array}{l}\text { Misguiding the public and a possible cause } \\
\text { that inhibits nanotechnological development }\end{array}$ \\
\hline Role of ethics & $\begin{array}{l}\text { Ethics should help to set, and verify, a moratorium } \\
\text { on nanotechnology }\end{array}$ & $\begin{array}{l}\text { Ethics is to improve the communication from } \\
\text { science to society and so to promote the further } \\
\text { development of nanotechnology }\end{array}$ \\
\hline
\end{tabular}

development, the possibility that ethics might inform the direction of technological development is neglected.

All three presuppositions that are shared by Joy and the NNI are problematic. First, there are good reasons to suppose that we hardly know yet what nanotechnology will bring for society; the ethical issues are by no means clear yet. This is not to say that we should neglect ethical concerns unless the consequences are clear or should wait until the ethical issues materialize. There are good reasons to try to address ethical issues in the early stages of nanotechnological development. One reason is that if we wait until the issues materialize, it might be too late to deal with them or to redirect the path of technological development. We should, however, try to keep an open mind about what the ethical issues in nanotechnology are and should recognize that ethical judgment about nanotechnologies is complex and debated.

Second, the reduction of ethics to communication rests on a misconception of what ethics is about. Ethics, as a philosophical discipline, aims at analyzing ethical issues and in providing arguments, pro and contra, certain positions. Even if one opposes the idea that ethicists are to decide on what is morally acceptable or not with respect to nanotechnology, and I think that are good reasons to object to such a role of ethical experts, the role of ethics is far richer than just improving communication. Ethics can help to clarify moral issues, to analyze them and to assess arguments.
Third, it is not advisable to restrict the role of ethics in nanotechnological development to just a simply yes or no. Like in other domains, ethical issues in nanotechnology are complex and cannot be answered by a simply yes or no. Nanotechnology has potentially great benefits to society and it seems unwise, if not immoral, to simply forbid all nanotechnological developments because there may be great dangers. Unrestricted development, without taking into account any possible negative effects on society or potential hazards, would also be unwise if not immoral. The way out of this dilemma is to be sought in promoting specific directions of technological R\&D and/or in specific measures to address ethical issues. For example, the knowledge that nanoparticles might be quite dangerous, and might become a of new kind of asbestos, is at least a strong prima facie moral reason to investigate the health effects of nanoparticles before products that use such particles are brought onto the market. I do not want to suggest that all moral dilemmas around nanotechnology can be easily solved in this way, on the contrary, but a viable approach to the ethics of nanotechnology should at least provide for the opportunity that ethics can inform the direction of nanotechnological R\&D.

\section{Does Nanotechnology Raise New Ethical Issues?}

Although the ethics of nanotechnology, or nanoethics as some prefer to call it, is still in its infancy, one 
issue has already raised a lot of discussion, i.e. whether any new ethical issues are raised by nanotechnology (e.g. [1, 10, 13, 15, 19]). What complicates this debate is that different authors have used different notions of 'newness' in this debate. At least two different notions can be distinguished, one is that an ethical issue is new if it is not raised by an existing technology or not dealt with in another field of applied ethics; another notion is that an ethical issue is new if we (still) lack adequate normative standards to deal with it.

Below, I will first discuss the different two meanings of newness in the debate about the newness of ethical issues in nanotechnology. I will then address the question in what respects it might be relevant, or not, to know whether ethical issues in nanotechnology are new.

\section{What is New?}

The first notion of newness is based on the idea that an ethical issue is new if it is not yet raised by another technology or not yet covered by another field of applied ethics. This notion of newness is, for example, used in the following quote from Søren Holm:

It is difficult to specify exactly what could make an area of technology so special that it needs its own ethics, but a minimal requirement must be that it either raises ethical issues that are not raised by other kinds of technologies, or that it raises ethical issues of a different (i.e. larger) magnitude than other technologies. Is this the case for nanotechnology? ([15]: 1).

Holm's answer is no. Grunwald [13] comes to a similar conclusion:

The propagation of nano-ethics overlooks the fact that many of the ethical questions raised by nanotechnology are already known from other contexts of ethical reflection. The ethics of technology, bioethics, the ethics of medicine or also the theoretical philosophy of technology concern themselves with questions of sustainability, of risk assessment, of the interface between human beings and technology, especially between living beings and technology. These questions are in themselves not new ... ([13]: 198).
Nevertheless, some ethical issues are new in nanotechnology according to Grunwald:

Partially new, however, is their [i.e. of the various ethical issues, IvdP] convergence in nanotechnology. Analogous to the well-known fact that nanosciences and nanotechnology are fields in which the traditional borders between physics, chemistry, biology, and the engineering sciences are crossed, various traditional lines of ethical reflection also converge in ethical questions in nanotechnology ([13]: 198).

Another issue that is often mentioned as being new is human enhancement. Although the striving for enhancement is as such not new, what is claimed to be new is enhancement by technological means [10, 13]. As Grunwald remarks: 'Technical enhancement of human beings themselves - if this would be possible at all —would in any case pose a series of new ethical questions' ([13]: 196).

\section{New Normative Standards?}

A second way in which ethical issues can be new is that they require new normative standards. Several authors have denied the need for new normative standards for nanotechnology. Chris MacDonald, for example, has stated that:

Ethical reflection on nanotech requires that we apply ethical principles to new domains, but it does not demand new principles. An example: As nanoscience spawns developments in nanomedicine, concerns arise related to experimentation on human subjects. These innovative treatments will sometimes use novel methods of delivery (e.g., drugs dispensed to tumors inside engineered molecules such as fullerenes). Yet the principles governing research will remain unchanged. Researchers must continue focusing on informed consent, risk minimization, and the protection of vulnerable populations [19].

A similar argument has been made by Søren Holm:

While there is thus a great need for ethical analysis of the many ethical issues raised by the different developments in nanotechnology, there is no need for a specific nanoethics. The toolbox developed in applied ethics during the last 
35 years probably already contains the necessary tools for the analysis of nanotechnology ([15]: 3).

Both authors thus argue that no new normative standards, methods or concepts in ethics are required to deal with the ethical issues in nanotechnology. Their arguments, however, seems to presuppose a rather deductive approach to applied ethics, in which existing normative principles, concepts or methods are applied to a new domain. Such a deductive approach to applied ethics has been criticized by several philosophers (e.g. $[2,20]) .^{5}$ The deductive approach has at least three shortcomings.

One problem of the deductive approach is what theory to apply. In moral philosophy, no agreement exists about normative standards. Different ethical theories have been developed like utilitarianism and other strands of consequentialism, deontology and virtue ethics which might lead to conflicting recommendations what to do in a concrete situation. In fact, discussions about human enhancement through nanotechnology and other technologies have already given rise to conflicting moral judgments (e.g. [10, 21]). This is not to argue against the use of ethical theory as such or to argue that moral disagreement is necessarily a bad thing, it is to point out that the idea that established ethical theories or standards are uncontroversial and can be applied to new moral problems as they arise-i.e. the core of the deductive approachis too simplistic.

Two, the application of normative standards is often not as straightforward as a deductive approach suggests. In many situations, different normative standards could be applied that yield inconclusive or contradictory results. Often, we deal with situations in which various normative standards conflict. Often these conflicts are rather situation-specific and it may be doubted whether any generally applicable algorithms to solve such moral conflicts exist. A main problem with the deductive approach is that it treats moral problems as abstract philosophical problems to be solved by the application of tools and normative standards from moral philosophy and applied ethics. However, actual moral problems always arise in a

\footnotetext{
${ }_{5}^{5}$ For an approach that tries to justice to normative principles and ethical theories without applying a deductive approach, see for example van de Poel and Royakkers [35].
}

specific context that partly defines the problem. For example, what moral norms and values are conflicting, and what kind of compromises or tradeoffs between such norms and values are possible is contextdependent and is not given by the mere fact that we are confronted with, for example, a privacy issue. So, even if both information and communication technology and nanotechnology raise privacy issues it cannot be concluded a priori that these privacy issues constitute the very same moral problem in both domains, and that solutions that are adequate in one domain can without problems be applied in the other domain.

Third, theory development in ethics does not take place, and cannot take place, completely independent of concrete situations. To some extent, theory development should be amendable to judgments about particular situations and should be developed in order to deal with concrete moral problems that arise in existing and new practices. In fact, new technological developments might problematize existing normative standards or moral concepts. Developments in bionanotechnology are for example expected to blur the morally relevant distinction between treatment of diseases and enhancement (cf. [4]: 418; [13]: 197). Such technical developments thus require the rethinking of certain morally relevant concepts and we cannot simply apply existing (moral) concepts and normative standards to deal with the ethical questions concerning human enhancement by nanotechnology.

The deductive approach is thus problematic. However, there might be other arguments why the ethics of nanotechnology does not require new normative standards. Such an alternative argument is offered by Grunwald $[4,13]$. According to Grunwald $[11,12]$, ethical issues in technology do not require ethical reflection if a normative framework exists that meet certain conditions, i.e comprehensiveness (the normative standards are sufficient to deal with the problem under consideration), unambiguity, local consistency, acceptance and compliance. If such normative frameworks indeed exist and cover the ethical issues raised by nanotechnology, there is no need to develop new normative standards for nanotechnology. Grunwald [13] and Brune et al. [4] discuss potential ethical issues in nanotechnology in the light of existing normative frameworks. They suggest that many ethical issues are already covered 
by existing normative frameworks, although some are not. Regretfully, their conclusions are not always entirely clear. For example, with respect to nanoparticles, they conclude that the type of ethical issues that are raised by nanoparticles are not new and are in fact already known from other field of risks ([4]: 409; [13]: 192). This suggests that a normative framework is already available. ${ }^{6}$ In the meantime, they say that ethical reflection could take place on questions like 'Which role do the-doubtlessly considerableopportunities of nano-particles based products play in considerations ...? Upon which criteria could benefits and hazards be weighed against each other when the benefits are (relatively) concrete, but the hazards are hypothetical?' ([4]: 408; see also [13]: 191). Raising this kind of questions suggests that we still lack a normative framework to make all relevant decisions about nanoparticles.

Apart from the question whether ethical issues in nanotechnology are covered by existing normative frameworks, doubts may be raised about how likely it is that such existing normative frameworks meet all conditions mentioned by Grunwald. It is true, for example, that regulative frameworks exist for the acceptance of technical risks, consisting for example of legal requirements and technical codes and standards. In many cases it may be doubted, however, whether these frameworks are accepted by all who are potentially affected by such risks, while such acceptance is one of the conditions that Grunwald formulates for the existence of a normative, instead of only a regulative, framework.

\section{Is It Relevant Whether Nanotechnology Raises New Ethical Issues or Not?}

One reason why the discussion about the newness of ethical issues in nanotechnology has come up is that some authors have argued for the need of a new field of nanoethics (e.g. [1, 23]). Arguments against the newness of ethical issues in nanotechnology are supposed to be a knock-down argument against a separate field of nanoethics (cf. the earlier quote from Holm). However, there may be other reasons - apart

\footnotetext{
${ }^{6}$ Another reading would be that this statement only deals with newness in the first sense that I discussed above.
}

from the alleged newness of ethical issues in nanotechnology - for establishing a separate field of nanoethics, for example because nanotechnology is now very visible and having a separate field of nanoethics may make the ethical issues also more visible and might provide a platform to discuss ethical issues with nanoscientists [1]. On the other hand, even if nanotechnology would raise new ethical issues there may be reasons not to have a separate field of nanoethics, or at least not to separate it too much from existing fields of applied ethics or from moral philosophy, for example, in order to prevent that insights from such other fields are overlooked in nanoethics, ${ }^{7}$ or to prevent that ethical issues in nanotechnology are too much separated from related ethical issues in other fields [13].

The newness of ethical issues in nanotechnology might after all not be that relevant. There is in fact a danger in focusing so strongly on the newness of ethical issues, i.e. that attention is drawn away from ethical issues that are maybe not entirely new but nevertheless pressing from a social point of view. Several authors have indeed stressed that ethical issues should be addressed even if they are not genuinely new (e.g. [15, 31]). The danger is, however, not only that ethical issues which are not genuinely new are not addressed, but also that such ethical issues are not discerned in the first place. One common presupposition in the whole debate on the newness of ethical issues in nanotechnology seems to be that we already know what the ethical issues are or will be. I think that there are good reasons to suppose that many important ethical issues will become clear as nanotechnology further develops and that some of the ethical issues that will arise depend on choices made in nanotechnological R\&D (cf. [31]: 51). What is needed then is an approach that makes it possible to discern and analyze ethical issues as nanotechnology develops.

\footnotetext{
${ }^{7}$ Ironically, this lack of awareness of insights from applied ethics or moral philosophy also seems apparent in some arguments against the newness of ethical issues in nanotechnology. This is for example the case for the apparent lack of awareness of well-known objections against the deductive model.
} 


\section{An Alternative Approach}

On the basis of the discussion of the two debates above, desiderata for an approach to discerning ethical issues in nanotechnology that substantially improves upon existing approaches can be formulated. First, it is desirable to develop an approach that is able to discern ethical issues in nanotechnology as they emerge during the further development of nanotechnologies and that does not presume that ethical issues are given or clear-cut. Second, such an approach should make it possible to use ethical insights to inform and steer nanotechnological R\&D and should not say simply yes or no to certain nanotechnological developments. Finally, such an approach should deal with ethical issues in their real-world context rather than taking them as abstract ethical issues that can be solved by applying existing ethical concepts and theories. ${ }^{8}$

I now turn to the description of an approach for discerning ethical issues in nanotechnology that addresses these desiderata. The approach itself is not peculiar to nanotechnology and has been described by me and my colleagues elsewhere [37]. The emphasis here is therefore not on a description of the approach itself but on its applicability to ethical issues in nanotechnology.

\section{Network Approach for Discerning Ethical Issues}

The network approach for discerning ethical issues has been developed to discern ethical issues in technological R\&D. R\&D settings are characterized by two features that complicate the discerning of ethical issues [37].

\footnotetext{
${ }^{8}$ On basis of the earlier discussion, one might want to add a fourth criterion: the method should conceive of ethics not only as means for communication but also as an analytical discipline. The reason I have not included this desideratum is that it refers to ethical analysis while I restrict myself here to an approach for discerning ethical issues. Nevertheless, the network approach outlined in this article certainly allows for a broader conception of ethics than just a means of communication. For more specific proposals how to combine ethical analysis with a network approach, see van de Poel et al. [34].
}

One is that there is usually a distance in time, place and involved parties between the R\&D activities and the eventual application of the technology that gives rise to social effects and ethical concerns. Nanotechnology is subject to the so-called Collingridge dilemma [6]: at the phase that we can still direct a certain technology, the ethical and social issues raised by that technology are not yet known or clear, while at the stage that these issues become clear or more well-defined, the possibilities of steering the technological development have declined considerably because the technology is more embedded in society.

The second feature that complicates the discerning of ethical issues is that usually various parties are involved in R\&D with different interests, visions, and degrees of power. The eventual R\&D trajectory and the ethical issues it raises will therefore be the result of the actions of these various actors, and is not determined by one actor.

The network approach we have developed deals with these two complicating factors by using the involved actors and potential stakeholders as an entry for discerning ethical issues while doing justice to the different perspectives and perceptions of the actors involved and the stakeholders. It does so, for example, through interviews and brain-storming sessions with the relevant actors and stakeholders (see [37] for a more detailed description).

Network approaches have become popular in a number of descriptive disciplines like policy science and science and technology studies over the last decades (e.g. [5, 14, 18, 25]). Such approaches have been introduced to take account of the fact that activities like technological development and policy making are not controlled by one actor but by a range of actors who are mutually dependent. It is, for example, generally recognized that technological R\&D takes place in networks of actors like universities, research institutes, corporations, government agencies, and prospective users. While current network approaches account for that, our contribution has been to adapt such an approach to the discernment of ethical issues. What is especially important here is to realize that different actors in an R\&D network have different interests, resources, knowledge and power, as well as different problem definitions and agendas. 'Problem definition' refers to 'the different actor perceptions or interpretations of what is the 
central issue in the network' ([37]: 671) 'Agendas' are 'coherent sets of goals or ends, which these actors want to achieve.' ([37]: 671). The agendas of various actors may be conflicting.

Actors in a network have different problem definition and agendas because they have different interests, resources, knowledge and power, as well as different belief and value systems. A belief or value system is a more or less coherent set of beliefs and values held by an actor. It consists in beliefs about concrete facts and with respect to specific normative issues, and in principles and background theories that an actor uses in arriving at, or justifying, his or her beliefs and values.

The main idea of the network approach for discerning ethical issues in $R \& D$ is that it is very helpful to identify differences between the problem definitions, agendas and belief and value systems of the actors in an R\&D network, and the dynamics of the network under consideration in order to discern ethical issues. Two examples from a project where we applied the network approach to discern ethical issues might illustrate this idea. This project concerned the development of a new technology for treating sewage.

One of the things that we discovered in this project by applying a network approach is that different actors made different estimates of the likelihood that the new treatment reactor would meet the primary, i.e. legally mandatory, treatment requirements. The projected users of the technology were more pessimistic in this respect than the researchers. This factual disagreement can be morally relevant for a number of reasons. One is that it might indicate insincerity on the side of the researchers; they may be more optimistic than warranted or may present the chances of meeting the requirements as larger than they actually believe to be true. This was, however, not the case in the specific project we researched. The disagreement might also be morally relevant because it can be an indication that public funds are not well spent: if the chances of meeting the primary requirements are dim, it is questionable whether such a project should receive public funding. Again, in our assessment, this was not the case here. The difference in estimate may also be relevant because if the primary requirements are not met it might create environmental and health problems. This is certainly a reason to pay enough attention to meeting the requirements.
Another issue on which different actors had different opinions related to so-called secondary emissions. These are emissions that are not yet regulated by the law, but are nevertheless relevant in terms of environmental pollution or health. Typically, sewage treatment plants remove, for example, pathogenic bacteria or heavy metals from sewage, while the required levels of treatment for such substances and organisms are not always laid down in the law. When a new reactor is developed, it might well be the case that it removes less secondary emissions than traditional reactors especially if the retention time of the sewage in the reactor is shorter. We found that there was an interesting, yet worrying, disagreement in the R\&D network about who should take care of investigating and possibly preventing higher secondary emissions. Most researchers thought that this should be done during the use phase, while most prospective users thought this issue should be addressed during the research phase. This situation may give raise to what is known as the problem of many hands [3, 32]: in situations in which a multiplicity of actors is involved it might be unclear who is responsible for what and for some issues it might well be the case that nobody assumes responsibility. It is not difficult to think of analogous situations in nanotechnology: who, for example, is - or should be-responsible for investigating the potential toxicity of nanoparticles? ${ }^{9}$

\section{The Applicability of the Network Approach} to Nanotechnology

Although the network approach is not specifically developed for nanotechnology, for a number of reasons, the approach is especially appropriate for discerning ethical issues in nanotechnology. I will focus here on the earlier mentioned desiderata.

First, ethical issues in nanotechnology are still unknown or in flux. To an important extent, this is due to the fact that nanotechnology is still in an early phase of development and to the distance between the research that is now being done in the scientific laboratories and the eventual applications. The net-

\footnotetext{
${ }^{9}$ For a discussion of some of the issues involved here, see Shrader-Frechette [29].
} 
work approach has been specifically developed to deal with these difficulties. It uses the researchers and the networks in which they participate, including the other relevant parties in these networks, as entry for discerning ethical issues. What is important is that ethical issues often do not arise at the level of individual researchers and engineers, but at more collective levels. The two examples from the development of a sewage treatment reactor illustrate this. For example, the problem that nobody assumes responsibility for investigating secondary emissions is only visible at the collective level at not at the level of individuals in isolation. The network approach is thus especially appropriate to discern ethical issues that arise at more collective levels.

Second, the network approach can be applied already at the early stages of technological development and addresses the researchers involved in nanotechnology. It can therefore generate insights that immediately influence R\&D and research and design decisions. In the earlier mentioned case of the sewage treatment reactor, the articulation of some ethical issues in fact has influenced the formulation of further technical research proposals. ${ }^{10}$

Third, the network approach discerns ethical issues in their real-world context. The people involved in R\&D and the relevant networks are used as entry for discerning ethical issues. This is not to say that issues are only seen as ethical if the actors themselves recognize them as such, the ethicist him- or herself has the room to articulate certain ethical issues even if the actors themselves do not recognize them as such. However, this articulation takes into account the empirical facts of the situation and is not just based on a heuristics of fear or an analogy with other technical domains or abstract philosophical considerations alone.

\section{Limitations and Challenges}

A major strength of the network approach is that is takes researchers and engineers, and the networks in which they participate, as entry for discerning ethical issues. Nevertheless, this characteristic also leads to a

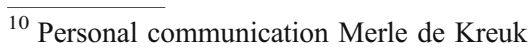

number of limitations and challenges for the network approach.

A first issue is that the network approach requires close collaboration with the people involved in nanotechnological $R \& D$ and requires a certain amount of mutual trust to be successful. ${ }^{11}$ A danger of this is that it might hamper the independence of the ethicists involved. They might feel compelled to be not too critical towards the nanotechnological researchers in order to successfully apply the approach. Although this is a real issue, it should not be overstated. I think this issue can be dealt with by a combination of personal skills and institutional safeguards. It requires skills to maintain a relation with the researchers that is based on trust, while it at the same time it leaves room to be mutually critical - it is important to realize that also the nanotechnological researchers should have the room to criticize the ethicists. Still, this type of interpersonal relation is quite common in science; also peers within the same scientific area have relations based on a combination of trust and criticism, and cooperation and competition. In addition, it would be desirable to establish institutional safeguards that protect the independence of the ethicists. Conversely, it should be recognized that for nanotechnological researchers there are also important stakes. Critical reporting about some nanotechnological development might hamper the funding of nanotechnological research or might make potential users more cautious. This places a certain responsibility on the shoulders of ethicists of being not too eager to report ethical worries if these are far-fetched or unrealistic. It also requires, I think, an institutional safeguard that gives nanotechnological researchers the possibility to react to claims made by ethicists or to complain about unwarranted claims.

A second issue is that the application of a network approach, especially if it focuses strongly on the researchers involved, might neglect certain perspectives on the relevant ethical issues, in particular the perspectives of those not directly involved but

\footnotetext{
${ }^{11}$ It also requires that the ethicists have some knowledge of nanotechnology, so that they understand what they are talking about and are able to identify ethical issues somewhat independent from the nanoscientists and engineers. This requirement is, however, not specific for a network approach but applies to any sensible approach to nanoethics.
} 
nevertheless affected by the technology. There are, however, various possibilities to avoid this. In applying the network approach, it is perfectly possibly to involve all kinds of relevant stakeholders, like, for example, researchers that are not part of the relevant R\&D network but work in a neighboring area.

Third, a network approach may fall short in dealing with broader ethical issues that transcend the boundaries of R\&D networks. One such issue is whether certain nanotechnological R\&D should be done at all or whether certain applications should be banned. For such decisions, insights of what is going on in R\&D networks and the type of ethical issues this raises is still relevant but the broader ethical issue transcends the boundaries of actual R\&D networks. This is also for example true for global justice considerations with respect to nanotechnology. Again, insights in what is going on in R\&D networks can be quite relevant here and sometimes R\&D decisions can influence whether global justice issues arise or not, for example by choosing one R\&D trajectory over another. ${ }^{12}$ Still, it can be argued that some of the issues involved are to be addressed at other locations than the R\&D networks. One way of dealing which such issues might be to look at nested networks. R\&D networks are embedded in other networks; this embedding is not morally neutral and may influence for example the way certain technologies that have been developed in R\&D networks are applied. ${ }^{13}$ So an extended network approach might be quite useful here.

Open Access This article is distributed under the terms of the Creative Commons Attribution Noncommercial License which permits any noncommercial use, distribution, and reproduction in any medium, provided the original author(s) and source are credited.

\footnotetext{
${ }^{12}$ For example, in the development of certain (nano)medicines for Third World countries R\&D trajectories towards medicines that are cheap and are not (or cannot be) patented are attractive while pharmaceutical companies might prefer trajectories towards more expensive and patentable medicine.

${ }^{13}$ Think for example about dual use technologies, i.e. technologies - like certain forms of nanotechnology - that can be used to both good and bad ends. Banning or not developing such technologies might be unattractive because it also foregoes the positive applications. Even if in some cases bad applications cannot be avoided by research or design choices, the actual probability of bad applications will at least partly depend on the way the relevant $R \& D$ and innovation networks are embedded in broader political and commercial networks.
}

\section{References}

1. Allhoff F, Lin P (2006) What's so special about nanoethics. Int J Appl Philos 20:179-190

2. Beauchamp TL (1984) On eliminating the distinction between applied ethics and ethical theory. Monist 67:514 531

3. Bovens M (1998) The quest for responsibility. Accountability and citizenship in complex organisations. Cambridge University Press, Cambridge

4. Brune H, Ernst H, Grunwald A, Grunwald W, Hofmann H, Krug H, Janich P, Mayor M, Rathgeber W, Schmid G, Simon U, Vogel V, Wurwa D (2006) Nanotechnology. Assessment and perspectives. Springer, Berlin

5. Callon M (1986) The sociology of an actor-network: the case of the electric vehicle. In: Callon M Law J, Rip A (eds) Mapping the dynamics of science and technology, sociology of science in the real world. Macmillan, Hampshire, pp 72-102

6. Collingridge D (1980) The social control of technology. Frances Pinter, London

7. Drexler KE (1986) Engines of creation. The coming era of nanotechnology. Anchor Books, New York

8. ETC Group (2003) The big down: from genomes to atoms. ETC Group, Ottawa

9. Gordijn B (2005) Nanoethics: from utopian dreams and apocalyptic nightmares towards a more balanced view. Sci Eng Ethics 11:521-533

10. Gordijn B (2006) Converging NBIC technologies for improving human performance: A critical assessment of the novelty and the prospects of the project. J Law Med Ethics 34:2-8

11. Grunwald A (2000) Against over-estimating the role of ethics in technology development. Sci Eng Ethics 6:181196

12. Grunwald A (2001) The application of ethics to engineering and the engineer's moral responsibility: Perspectives for a research agenda. Sci Eng Ethics 7:415-428

13. Grunwald A (2005) Nanotechnology-a new field of ethical inquiry. Sci Eng Ethics 11:187-201

14. Hakansson H (ed) (1989) Industrial technological development. A network approach. Routledge, London

15. Holm S (2005) Does nanotechnology require a new "nanoethics"? Cardiff Centre for Ethics, Law and Society, August 2005. Retrieved October, 26, 2007, from http:// www.ccels.cf.ac.uk/archives/issues/2005/

16. Jonas H (1984) The imperative of responsibility; in search of an ethics for the technological age. University of Chicago Press, Chicago

17. Joy B (2000) Why the future doesn't need us. Wired 23862 April

18. Klijn EH (1997) Policy networks. An overview. In: Kickert WJM, Klijn EH, Koppenjan JFM (eds) Managing complex networks. Strategies for the public sector. Sage, London, pp 14-34

19. MacDonald C (2004) Nanotech is novel; the ethical issues are not. The Scientist 18:8

20. McIntyre A (1984) Does applied ethics rest on a mistake. Monist 67:498-513 
21. Miller P, Wilsdon J (eds) (2006) In: Better humans? The politics of human enhancement and life extensions. DEMOS, London

22. Mnyusiwalla A, Daar AS, Singer PA (2003) "Mind the gap': Science and ethics in nanotechnology. Nanotechnology 14: R9-R13

23. Moor J, Weckert J (2004) Nanoethics: assessing the nanoscale from an ethical point of view. In: Baird D, Nordmann A, Schummer J (eds) Discovering the nanoscale. IOS, Amsterdam, pp 301-310

24. Nordmann A (2007) If and then: a critique of speculative nanoethics. Nanoethics 1:36-46

25. Pinch T, Bijker W (1987) The social construction of facts and artifacts. Or how the sociology of science and the sociology of technology might benefit each other. In: Bijker W, Hughes TP, Pinch T (eds) The social construction of technological systems; new directions in the sociology and history of technology. MIT, Cambridge, pp $17-50$

26. Roco MC, Bainbridge WS (eds) (2001) Societal implications of nanoscience and nanotechnology, Arlington

27. Schummer J (2004) "Societal and ethical implications of nanotechnology": Meanings, interest groups, and social dynamics. Techne 8:56-87

28. Schummer J (2007) Identifying ethical issues of nanotechnologies. In: H. ten Have (ed) Nanotechnology: Science, ethics and politics, Paris, pp 79-98
29. Shrader-Frechette KS (2007) Nanotoxicology and ethical conditions for informed consent. Nanoethics 1:47-56

30. Swierstra T, Rip A (2007) Nano-ethics as NEST-ethics: patterns of moral argumentation about new and emerging science and technology. Nanoethics 1:3-20

31. The Royal Society and The Royal Academy of Engineering (2004) Nanoscience and nanotechnologies: Opportunities and uncertainties. The Royal Society and The Royal Academy of Engineering, London

32. Thompson DF (1980) Moral responsibility and public officials. Am Polit Sci Rev 74:905-916

33. UNESCO (2006) The ethics and politics of nanotechnology. UNESCO, Paris

34. van de Poel I, Brumsen M Zwart S, van Mil H (2004) Normative reflections on sociotechnical networks in the development of a new wastewater treatment reactor in the netherlands. Paper presented at Workshop New Directions in Understanding Ethics and Technology, Charlottesville

35. van de Poel I, Royakkers L (2007) The ethical cycle. J. Bus Ethics $71: 1-13$

36. White House Office of the Press Secretary (2000) National nanotechnology initiative. Leading to the next industrial revolution. Retrieved June, 20, 2007, from http://clinton4. nara.gov/WH/New/html/20000121_4.html

37. Zwart SD, Van de Poel I, van Mil $\bar{H}$, Brumsen M (2006) A network approach for distinguishing ethical issues in research and development. Sci Eng Ethics 12:663-684 